\title{
High-throughput computational screening of porous polymer networks for natural gas sweetening based on neural network
}

\author{
Xuanjun $\mathrm{Wu}^{1}$, Yujing $\mathrm{Wu}^{1}$, Xiuyang $\mathrm{Lu}^{1}$, Zhixiang $\mathrm{Cao}^{1}$, Xionghui $\mathrm{Wei}^{2}$, and Weiquan $\mathrm{Cai}^{3}$ \\ ${ }^{1}$ Wuhan University of Technology \\ ${ }^{2}$ Peking University \\ ${ }^{3}$ Guangzhou University
}

January 6, 2021

\begin{abstract}
17,846 PPNs with the diamond-like topology were computationally screened to identify the optimal adsorbents for the removal of $\mathrm{H} 2 \mathrm{~S}$ and $\mathrm{CO} 2$ from humid natural gas based on the combination of molecular simulation and machine learning algorithms. The top-performing PPNs with the highest adsorption performance scores (APS) were identified based on their adsorption capacities and selectivity for $\mathrm{H} 2 \mathrm{~S}$ and $\mathrm{CO} 2$. The strong affinity between water molecules and the framework atoms has a significant impact on the adsorption selectivity of acid gases. We proposed two main design paths (LCD [?] 4.648, Vf [?] 0.035, PLD [?] 3.889 or 4.648 [?] LCD [?] 5.959 , P [?] $837 \mathrm{~kg} \cdot \mathrm{m}-3)$ of high-performing PPNs. We also found that artificial neural network (ANN) could accurately predict the APS of PPNs. N-rich organic linkers and highest isosteric adsorption heat of H2S and $\mathrm{CO} 2$ are main factors that could enhance natural gas sweetening performance.
\end{abstract}

\section{Hosted file}

hPPNs4H2S_MAIN_plain.DOCX available at https://authorea.com/users/387637/articles/502625high-throughput-computational-screening-of-porous-polymer-networks-for-natural-gassweetening-based-on-neural-network 